pp. $551-562$

\title{
The Impact of Undergraduate's Socio-Demographic Characteristics on the Risk of Deviant Financial Behavior
}

\footnotetext{
Submitted 23/06/20, 1st revision 12/07/20, 2nd revision 17/08/19, accepted 10/09/20

\author{
Ludmila I. Nivorozhkina ${ }^{1}$, Elena N. Alifanova ${ }^{2}$, Yulia S. Evlakhova ${ }^{3}$, \\ Alexandra A. Tregubova ${ }^{4}$
}

Abstract:

Purpose: The paper demonstrates the authors ' approach for the identification of groups of individuals who are prone to manifestations of various deviations in financial behavior.

Design/Methodology/Approach: The research is based on empirical data from a survey of 912 senior students using a specially designed questionnaire. Applying a latent class analysis technique we distribute students into groups that differ in their attitude toward money, financial literacy, financial strategies, risk appetite, and a propensity to deviant behavior.

Findings: The study showed that more prone to deviant financial strategies are mainly young men, prone to financial risk, enrolled in the commercial form of education, natives of regional subordination cities, those who not inclined to innovative financial strategies. More likely to be involved in illegal financial schemes those who we classified as "spendthrifts" from families without high income, "savers" and "reasonable" from high-income families.

Practical Implications: Research results can be used to formulate policies to improve population financial literacy, as well as to adjust economic policy in general. There is a need for financial education programs to pay special attention to the issues of countering fraud, preventing involvement in money laundering and terrorism financing (ML/FT) processes.

Originality/Value: The socio-demographic portrait of students most likely to engage in illegal financial strategies is not clearly formed. Individuals may be subject to financial deviations in some cases, with the purposeful influence of certain persons or circumstances.
}

Keywords: Deviant financial behavior, financial behavior of the population, financial literacy, attitude toward money, latent class analysis (LCA), multinomial logistic regression.

JEL codes: $C 25, C 3, C 5, D 14$.

Paper type: Research article.

Acknowledgments: The reported study was funded by RFBR according to the research project No. 18-010-00657.

\footnotetext{
${ }^{1}$ Rostov State University of Economics, Rostov-on-Don, Russian Federation, e-mail: lin45@mail.ru

${ }^{2}$ Rostov State University of Economics, Rostov-on-Don, Russian Federation, e-mail: alifanovaen@mail.ru

${ }^{3}$ Rostov State University of Economics, Rostov-on-Don, Russian Federation, e-mail: evlahova@yandex.ru

${ }^{4}$ Rostov State University of Economics, Rostov-on-Don, Russian Federation, e-mail: alexandra_a_t@mail.ru
} 


\section{Introduction}

The system of economic security is usually studied at the macrolevel, as well as at the level of financial institutions. However, the risks, significant in terms of social economic security in countering money-laundering and the financing of terrorism, may arise from interaction between financial institutions and individual customers. The reasons for deviations in financial behavior may be found in both objective economic factors and personal characteristics of individuals. This results in the need for methods to identify groups of individuals prone to show different deviations in financial behavior.

\section{Methodology}

The authors developed the approach suggested in their previous works (Nivorozhkina and Sinyavskaya, 2012; 2014; 2016; Sinyavskaya, 2014; Nivorozhkina et al., 2014) based on the assumption that a certain system of basic personal, behavioral, socio-economic and demographic characteristics and attitudes shapes a typology resting on the tendency to show deviations in financial behavior. Identification of the characteristics reflecting complex, basic drives of a certain side of individual financial activity, literacy, attitude to money, the level of maturity of ethical, moral imperatives regarding different actions when arranging personal finances, is presented as an individual questionnaire. Financial behavior stereotypes of many people, who were born and grew up in the socialist era, are influenced by the ideology of the past, and this must be taken into consideration when their strategies are analyzed and predicted.

Therefore, to test the proposed methods, a survey was conducted among students in their final years, studying at the largest higher educational institutions in the South of Russia. The choice of the interviewees stems from the fact that young people entering the labor market, firstly, grew up in a market economy, and secondly, they are to form the core of economically active population in the near future. That is why, to estimate their maturity and preparedness for financial behavior meeting the accepted standards seems relevant.

The questionnaire, reflecting conceptual provisions on an individual's financial behavior, has a complex structure aggregated in six blocks.

The first block is the block of individual financial estimations and decisions. It is used to estimate how well young people are familiar with financial services and what strategies they are planning to take in the future. The second block of the questionnaire is aimed at identifying the level of financial literacy, and is divided into four sections: "general financial knowledge", "savings and borrowings", "insurance", and "investment". It is important to note that the questions are specially framed to identify individual, everyday financial knowledge necessary for every individual receiving and distributing personal finances (Nivorozhkina et al., 2018a; 
2018b). The third block of attitudes regarding deviations in financial behavior contains five questions. When answering them, the interviewees need to express their attitude towards the situations described as neutrally as possible so as not to evoke any strong associations with the breach of legislative or ethical norms. These questions cover "under the table" salary, multiple pawning of valuable things at a friend's or relative's request, entrepreneurial activities without getting a selfemployed status, unofficial "signs of appreciation" for certain services, undervaluation of the apartment's cost when selling it to cut the amount of tax.

The questionnaire's blocks aimed at identifying the attitude to money (block four) and risk proneness (block five) are presented in the form of 71 statements to agree or disagree with. 60 statements aimed at identifying the attitude to money are taken from Furnham's and Argyle questionnaire (1998) and supplemented by 10 questions from the Eysenck Personality Questionnaire transformed into statements (Eysenck, 2017). To estimate the individual's risk proneness, a set of statements was supplemented by a control question. It rests upon the classic theoretical statement that, facing the choice between a probabilistic game and a guaranteed sum equal to the average win, a risk-prone individual will choose the game, and a risk-averse individual will choose the risk-free sum (Neumann and Morgenstern, 2004).

The questions grouped in block six, aiming at identifying respondents' awareness of actions against illegal financial transactions and their propensity for such transactions due to lack of information and credulity, reflect the response to requirements by the Federal Law "On countering the legalization of illicit gains (money laundering) and terrorism financing" Federal Law (2001) Article 6, stipulating the list of transactions with money or any other belongings subject to mandatory control.

The questionnaire's six main topic-specific blocks are supplemented by the socioeconomic and demographic block. These are questions about the respondent's gender, age, nationality, state-subsidized or commercial education, place of residence, total monthly expenditure, number of family members and dependents among them, the family's average monthly income, parents' level of education and activity status, the type of settlement and region of residence before entering the educational institution. The questionnaire also includes questions aimed at identifying the financial behavior characteristics typical for the young person's family, as there is probable cause to assume a connection between the family financial practice and financial strategies of individual family members ${ }^{5}$.

It has been said that conceptually blocks of questions are phrased with regard to internal structure linking its defining features. As a result, the students answering the questions are implicitly arranged in this feature space according to their individual preferences and socio-demographic features into certain a priori unknown groups.

\footnotetext{
${ }^{5}$ The text of the questionnaire is available on request: lin45@mail.ru.
} 
The number of these groups is significantly lower than the original number of features characterizing respondents' certain behavioral drives. Such conceptual multidimensional groupings include the ones characterizing the attitude to money, financial literacy, financial strategies planned for the future, risk proneness, and, of course, proneness to deviant behavior.

\section{Estimation Method}

The grouping of the interviewed students, different in their attitudes to money and future financial plans, requires, in our opinion, latent class analysis (LCA), which constitutes a set of mathematical methods to remodel an unknown genuine structure of links between experimental variables. LCA allows to identify and understand these unobservable groups, to determine possible members of the group, and how characteristics of one group are different from other groups. A latent categorical variable is used to represent the groups, while the groups themselves are called classes.

It is assumed that the social attitude under study (financial strategy, attitude to money) numerically represents some hypothetical (latent) continuum, where the studied students are distributed according to the certain value of their attitude. The answers to the questions, asked to specify financial strategies and attitude to money, reflect the external empirical structure of the phenomenon under analysis. The individuals are distributed in this continuum in accordance with a certain value of their social attitude (Lazarsfeld and Henry, 1968). STATA 15 package is used to implement the introduced approach (STATA, 2020).

\section{Information Base}

The initial data for the analysis was taken from the survey conducted among over 900 final year students of higher educational institutions in the South of Russia in the second half of 2018. A scheme of multi-stage random sample was developed for the interview (Nivorozhkina et al., 2018a).

\section{Results}

By the LCA method, the authors classified a subset of questions characterizing financial strategies of the undergraduates and their parents, as well as the undergraduates' attitude to money (Nivorozhkina and Alifanova, 2019). The students were asked the following question: "You are about to graduate from the higher educational institution and you will have to plan your finances. Let us assume that the forecast horizon is the nearest 10 years. You begin..."6.

\footnotetext{
${ }^{6}$ When choosing a strategy, it is possible to tick more than one point. Each type of strategy is transformed into a binary variable, which equals to one, if the student chooses the answer "yes", and it equals to zero in any other case.
} 
Analysis of the responses indicated that over a quarter of the interviewed (26\%) trust Sberbank as the most trustworthy financial institution. The runner-up strategy is spending all money on everyday life (19.4\%). However, a significant number of undergraduates are planning to buy shares and securities $(15.9 \%)$, they do not trust such a reliable instrument as federal bonds. Investment of funds in banks is more preferable in rubles rather than in foreign currency, however when money is not kept in banks, it is more preferable to do so in foreign currency. It can be assumed that the interviewed students can be classified according to their financial strategies into several different groups. For example, these can be groups with prevailing strategies of wastefulness or savings, risk strategies, etc. However, given that the respondents could choose several answers, the principle of such grouping is unclear, as the variable defining group affiliation is unknown.

The most informative and compact were the results of LCA classification into three classes. Table 1 demonstrates probabilities of a positive answer for each student grouped into a certain class according to his/her financial strategies.

Table 1. Classification of respondents by the types of their financial strategies

\begin{tabular}{|l|l|l|l|}
\hline Strategies & Class 1 & Class 2 & Class 3 \\
\hline $\begin{array}{l}\text { Saving up rubles in Sberbank as the most } \\
\text { trustworthy financial institution }\end{array}$ & 0.38 & 0.14 & 0.02 \\
\hline $\begin{array}{l}\text { Saving up currency in Sberbank as the most } \\
\text { trustworthy financial institution }\end{array}$ & 0.20 & 0.18 & 0.00 \\
\hline $\begin{array}{l}\text { Saving up money in rubles and placing it into } \\
\text { deposit accounts in commercial banks offering the } \\
\text { highest interest rates }\end{array}$ & 0.21 & 0.15 & 0.09 \\
\hline $\begin{array}{l}\text { Saving up money in currency and placing it into } \\
\text { deposit accounts in commercial banks offering the } \\
\text { highest interest rates }\end{array}$ & 0.14 & 0.22 & 0.00 \\
\hline Buying shares and securities & 0.11 & 0.53 & 0.02 \\
\hline Buying federal bonds (OFZs) & 0.01 & 0.16 & 0.00 \\
\hline Investing in open-ended funds & 0.00 & 0.26 & 0.00 \\
\hline $\begin{array}{l}\text { Buying currency (dollars, euros, etc.) and keeping } \\
\text { it in a safe place, but not in banks }\end{array}$ & 0.13 & 0.14 & 0.18 \\
\hline $\begin{array}{l}\text { Saving up money in rubles and keeping it in a safe } \\
\text { place, but not in banks }\end{array}$ & 0.04 & 0.10 & 0.41 \\
\hline Spending all money on everyday life & 0.27 & 0.00 & 0.15 \\
\hline Other (specify) & 0.06 & 0.05 & 0.03 \\
\hline Don't know & 0.00 & 0.00 & 0.36 \\
\hline Number of respondents, \% & 65.68 & 14.47 & 19.85 \\
\hline
\end{tabular}

Source: Own study.

Probability analysis of financial strategies for the most numerous Class 1 shows that undergraduates are going to spend the biggest share of their future income on their current needs and deposit spare money in Sberbank or in commercial banks with high interest rates. Currency will also be deposited in Sberbank. This type of 
financial behavior is characteristic of a significant part of Russian households, which is why we called it "Traditional". Class 2 is characterized by financial strategies of young people prone to search new opportunities in increasing their wellbeing, not afraid to run a risk. They are going to buy shares and securities, invest money into open-ended funds. They plan to deposit their savings in currency in commercial banks offering high interest rates. We called this type of financial behavior "Innovative". The strategies of Class 3 only showed intentions to save up money in rubles and store it in a safe place, whereas banks are not included into the range of reliable objects for keeping money. Besides, 36.0\% of respondents in this group found it hard to choose any of the offered range of strategies. That is why this type of financial behavior was called "Archaic".

With regard to the questions on attitude to money, the Table with distribution of the answers and classification results are available upon request, since there are over 70 questions in this part $^{7}$.

LCA method resulted in distinguishing three classes as well. However, despite differences revealed by identification of hidden patterns defining distinctions between the interviewed students, common features in attitudes to money have been determined. Young people's fundamental drive in their attitude to money consists in their negative attitude to debts (both borrowings and lendings). All respondents mentioned that when buying something, they always think about the price, don't like overpaying, and get upset when it happens. Saving up money in case of contingencies is also common for the respondents, as they can suddenly need money in an unforeseeable situation. In the majority's point of view, however, there is always a shortage of money. Nevertheless, all respondents understand limitation of money and support the opinion that money can't buy everything; there are things money cannot buy. For young people, power and people's opportunities are closely related to money, as, in their opinion, people are judged by their money in Russia. All respondents find it improper to ask others about their income.

So, how are undergraduates different in their attitude to money? In Class 1, the attitude to money unites young people who know exactly how much money they have in their wallets, but who are reluctant to spend it. They are characterized by the tendency to think carefully before making a decision to spend money; they prefer buying durable goods to food products or flowers; they also pay their bills carefully. These young people find it quite natural to be proud of their (potential) financial success, but at the same time they believe it is not worth telling their friends and relatives about details of their current financial situation. Dreaming about material well-being, they are ready to do a lot for money, but only within the law. This class is given the name "Savers". The share of respondents belonging to this class is $43.75 \%$.

\footnotetext{
${ }^{7}$ For enquiries about the listing with answers to the block of question on the attitude to money, please send an e-mail to: lin45@mail.ru.
} 
The representatives of Class 2 are young people tending to think over their future actions, paying their bills carefully. When purchasing something, the first thing they think about is the price as well. However, their drives are not as intensive as the drives of representatives of Class 1 . They do not dream about their future financial success and wealth, do not hide their savings and expenditures from the people around them, and do not wonder what they could do for money. We called this class "Reasonable", its share being 36.18\%.

In Class 3, as opposed to the first two classes, young people find it hard to control their financial state and believe that it doesn't depend upon their own personal efforts. They constantly worry about their financial situation and experience difficulties when they need to make a decision on spending their money, irrespective of the sum. They often dispute upon money with their parents and partners and when asked about their financial situation, they get anxious and adopt a defensive position. The representatives of this class often spend money on themselves when they are in a bad mood, they are prone to buy things they don't need. They find an incentive to buy something when the price is lower, or there is deficit of goods, moreover, when they can impress others putting on fashionable clothes. However, every time they buy something, they understand that people are likely to "make use" of them. Nevertheless, when paying in restaurants, buying tickets in cinemas and so on, they often insist that their share should be bigger. They dream about money, and they are certain that money can solve all problems, so they are ready to do anything to get more money! This class is referred to as "Spendthrifts", and their share is $19.85 \%$.

Classification by the level of financial literacy was developed by counting correct answers to the questions on financial literacy. If the number of correct answers surpassed the median value, the respondent was attributed to the financially literate group. The share of respondents in this group was $44.30 \%$.

Grouping based on risk attitude rests upon the "classic" understanding of the individual's financial risk inclination / aversion based on the von NeumannMorgenstern utility theory (Neumann and Morgenstern, 2004). It is believed that if an individual is offered to participate in a game (lottery), with a chance to win or lose, or to receive a guaranteed sum equal to the average win, a risk-prone individual will be more likely to choose the game (Nivorozhkina and Sinyavskaya, 2016). If the respondent chose to take part in the lottery, he was attributed to the risk-prone group, $23.00 \%$ of the interviewed were classified as such (Nivorozhkina et al., 2019).

As we have mentioned before, the block of questions aimed at identifying the individual's drives regarding deviations in financial behavior is presented as five questions in which the respondent needs to express his opinion on "under the table" salary, multiple pawning of valuable things at a friend's or relative's request, entrepreneurial activities without getting a self-employed status, unofficial "signs of appreciation" for certain services, undervaluation of the apartment's cost when 
selling it to cut the amount of tax. They characterize the most common deviations in financial behavior. The complexity of wording such kinds of questions is due to the fact that, when asked about their attitude to known violation of the law, respondents will predictably give a negative answer in most cases. We characterized respondents as prone to deviant behavior (finding it acceptable) if they gave two or more positive answers to the five questions listed above. The share of such respondents is $12.94 \%$.

We assume that the attitude to money and proneness to breaking the norms of financial behavior are interrelated, and their combinations form groups of respondents different in economic behavior. To test this hypothesis, we singled out the respondents who:

$>$ had a tendency to financial deviations and were attributed to Class 1, "Savers", according to their attitude to money (1 1);

$>$ had a tendency to financial deviations and were attributed to Class 2, "Reasonable", according to their attitude to money (1 2);

$>$ had a tendency to financial deviations and were attributed to Class 3, "Spendthrifts", according to their attitude to money (1 3);

$>$ had no tendency to financial deviations and were attributed to Class 1, "Savers", according to their attitude to money (0 1);

$>$ had no tendency to financial deviations and were attributed to Class 2, "Reasonable", according to their attitude to money (0 2);

$>$ had no tendency to financial deviations and were attributed to Class 3, "Spendthrifts", according to their attitude to money (l 3 ).

Table 2. Joint distribution by tendency to financial deviations and multi-dimensional classification by attitude to money ${ }^{8}$

\begin{tabular}{|l|l|l|l|l|}
\hline \multirow{2}{*}{$\begin{array}{l}\text { Characteristics } \\
\text { of the groups }\end{array}$} & \multicolumn{2}{|l|}{ Attitude to money } & \multirow{2}{*}{ Total } \\
\cline { 2 - 4 } & Class 1 & Class 2 & Class 3 & \\
\hline No tendency to financial deviations & $355\left(\begin{array}{lll}0 & 1\end{array}\right)$ & $285\left(\begin{array}{ll}0 & 2\end{array}\right)$ & $154\left(\begin{array}{ll}0 & 3\end{array}\right)$ & 794 \\
\hline Prone to financial deviations & $44\left(\begin{array}{llll}1 & 1\end{array}\right)$ & $45\left(\begin{array}{ll}1 & 2\end{array}\right)$ & $29\left(\begin{array}{ll}1 & 3\end{array}\right)$ & 118 \\
\hline Total & 399 & 330 & 183 & 912 \\
\hline
\end{tabular}

Source: Own study.

It should be noted that the tendency to deviations in financial behavior was identified for $12.93 \%$ of the respondents. For example, the "Savers" (37.29\% of those ready to breach financial norms) are ready to do anything within the law for money, whereas the "Spendthrifts" $(24.58 \%)$ are ready for anything, including breaking the law. The respondents showing no tendency to financial deviations value money differently as well. So, it is quite reasonable to assume that certain differences between the identified groups may be determined by personal, behavioral characteristics, such as

\footnotetext{
${ }^{8}$ For convenience of further presentation, the identified groups classified by inclination to deviations in financial behavior and attitude to money will be denoted by the numeric codes assigned to them.
} 
proneness to risk, financial literacy, and financial strategies. Besides, respondents' sociodemographic characteristics (gender, form and field of studying) also influence their plans and tendencies in financial behavior. Young people interviewed in the survey have not yet entered their independent working life, so family relations have a profound impact upon them. To take the influence of these factors into account, we need to consider the income of the family and the money allocated to the student for personal spending, parents' level of education and the character of their employment.

In the light of their multilayer classification by attitude to money, joint analysis of young students' inclination / aversion to deviant financial behavior is possible on the basis of the multinomial logistic regression model, where the dependent variable includes more than two categories on the nominal scale of measurement (Bühl and Zöfel, 2005). The results of the multiple logistic regression estimation are available upon request". The fourth category "having no tendency to financial deviations while belonging to the "Savers" class" $\left(\begin{array}{ll}0 & 1\end{array}\right)$ was used as a reference, and response models were estimated. Model 1 was "having a tendency to financial deviations and attributed to the "Savers" class" (1 1), model 2 - "having a tendency to financial deviations and attributed to the "Reasonable" class" $(12)$, model 3 - "having a tendency to financial deviations and attributed to the "Spendthrifts" class" (13), model 4 - "having no tendency to financial deviations and attributed to the "Reasonable" class" (0 2), model 5 - "having no tendency to financial deviations and attributed to the "Spendthrifts" class" $\left(\begin{array}{ll}0 & 3\end{array}\right)$.

Let us consider the interpretation in terms of predominance correlations or odds ratios. The first equation estimates the odds ratio for the respondents "with a tendency to financial deviations and attributed to the "Savers" class" as opposed to the respondents "without a tendency to financial deviations and attributed to the "Savers" class". For them, the odds that they will choose the chance to risk are higher than risk aversion. As higher educational institutions are usually concentrated in regional centers, the data set of the model suggests that out-of-town newcomers are predominant among the students of this group. The respondents with financial strategies attributing them to the innovative class are rarely classified into this group. Sociodemographic factors, the form and field of studying do not influence Group (11) affiliation. The odds to belong to the family with a high income are higher for them. In case the father is a company owner and the mother is a state owned enterprise employee, the odds to get into the Group (11) reduce. The second equation estimates the odds ratio for the respondents "with a tendency to financial deviations and attributed to the "Reasonable" class". They are also more likely to choose risk. For them, the odds to come to study from regionally governed cities are higher than to come from regional centers, whereas the odds to come from a village are lower. The family income does not influence their odds to get into Group (12).

\footnotetext{
${ }^{9}$ For enquiries about the results of the multiple logistic regression estimation, please send an e-mail to:lin45@mail.ru.
} 
The odds that the respondent in this group is a man are 3.8 times higher! These students prefer a rented or their own flat to a dormitory. The chances of getting in this group are statistically higher if both parents have a higher education and are employed. The respondents attributed to Group (13) also show a higher tendency to risk, their share being lower among those belonging to the class of people with innovative financial strategies. Most of them came to study from regionally governed cities, from families with an average or high income. The odds that the student from Group (12) is male are four times higher than female. The odds that the respondent is a commercial student are 2.8 times higher than a state-subsidized student.

The students from Group ( 02 2) belong to those who did not show any inclination to breach the norms of financial behavior. They are different from the reference in a less outspoken aspiration for money. Among them, young men are 1.5 times more numerous than young women. They are completely indifferent to risk, but their odds to belong to the group with innovative financial strategies are higher. Most of them come from high income families.

The final model Group (0 3) showed that the odds to be statistically literate are 50\% lower for its members, than the equivalent chances in the reference group $\left(\begin{array}{ll}0 & 1) \text {. The }\end{array}\right.$ odds to belong to the class of people with innovative financial strategies here are also lower than in Group (0 1). The odds to be studying in the field "Economics and management" for them are lower, and the odds are higher for the field of Humanities and Social Sciences. These students' chances to belong to high income families are higher.

The results obtained made it possible to identify the most characteristic features of the sociodemographic portrait of undergraduates in the South of Russia, indicating their potential inclination (aversion) to deviant behavior when dealing with their personal finances.

All students with detected inclination to deviant behavior had higher chances to choose a more risky situation among those arising in their lives. However, it should be noted that, with respect to this variable the coefficients of the model were not statistically relevant; therefore we believe it is possible to regard this as a weakly marked tendency. A higher financial literacy was shown by the students classified as "Reasonable", regardless of their tendency to deviations.

However, with respect to this conceptually relevant variable, all coefficients of the model turned out to be statistically irrelevant. Statistically relevant lower chances to follow innovative financial strategies were detected among deviations-prone "Savers" and, regardless of their deviations-proneness, "Spendthrifts". The type of settlement, where the student comes from to get education, does not play any statistically relevant role in the student's affiliation with the identified groups, except "deviations-prone Spendthrifts", whose chances to come from regionally 
governed cities are higher. Statistically relevant high level of family income is characteristic of the groups not inclined to deviant behavior. The choice of the extended group for fields of studying turned out to be statistically relevant only for the "Spendthrifts showing no tendency to financial deviations", who prefer to study Humanities. Young men predominate in the group of the "Reasonable", regardless of their tendency to deviations; the greatest odds for young men are to be attributed to the group of "Spendthrifts with a tendency to financial deviations". Commercial students predominate among them.

\section{Conclusions}

According to the framework adopted in the given study, there are almost thirteen percent of students who can potentially get involved in illicit activities. The estimation of their proneness to deviant financial behavior showed that, although sociodemographic portrait of young individuals most inclined towards risky financial strategies, including involvement in money laundering and financing of terrorism, has not been clearly defined yet, the analysis carried out in the research identified its key characteristics, which could become the basis for differentiation of this group of students from other groups.

They include prone to financial risk, mostly male commercial students coming from regionally governed cities with population over 100,000 citizens, showing no tendency to innovative financial strategies, "Spendthrifts" according to the type of financial behavior, from families without a high level of income, or "Savers" and "Reasonable" from families with a high income and a high level of education of working parents. We have identified a wider range of deviant financial behavior characteristics not only for undergraduates, relevant for the characteristics of the portrait under study, but for other classes of respondents as well. This means that, despite their lack of key characteristics, they can be prone to deviations in some cases, under deliberate influence of certain individuals or circumstances.

This result represents a signal of social immaturity of the bigger part of the young generation entering their independent lives. In this regard, it is important to form a system of education resulting in the moral, ethical imperative, which would not let young people breach the norms set by the law or society. Besides, considering young people's vulnerability to the deliberate negative influence, to involvement into illicit activities, it is necessary to pay special attention to the issues of fraud management and prevention of involvement into money laundering and financing of terrorism in financial education programs.

\section{References:}

Bühl, A., Zöfel, P. 2005. SPSS Version 10. Einfuhrung in die moderne Datenanalyse unter Windows. Pearson Studium.

Eysenck, H.J. 2017. Know Your Own I.Q. London, Penguin Books Limited. 
Federal Law. 2001. On countering the legalization of illicit gains (money laundering) and terrorism financing. Available at: http://www.fedsfm.ru/content/english/legal\%20basis/115-\%D1\%84\%D0\%B7-en.doc.

Furnham, A., Argyle, M. 1998. The Psychology of Money. London, Psychology Press.

Lazarsfeld, P.F., Henry, N.W. 1968. Latent Structure Analysis. American Sociological Review, 2(34)

Neumann, J., Morgenstern, O. 2004. Theory of games and economic behavior. New Jersey, Princeton university press.

Nivorozhkina, L.I., Alifanova, E.N. 2019. Financial strategies of university graduates: fathers and children (experience of statistical analysis). State and municipal management. Scholar notes, 138-146.

Nivorozhkina, L.I., Sinyavskaya, T.G. 2012. The concept of statistical risk assessment of involvement of clients of financial institutions in money laundering schemes. Terra Economicus, 4(10), 30-36.

Nivorozhkina, L.I., Sinyavskaya, T.G. 2016. Statistical methodology of risk assessment of financial behavior. Rostov-on-Don, Rsue publishing.

Nivorozhkina, L.I., Sinyavskaya, T.G. Novikov, D.S. 2014. Statistical evaluation of student's exposure to financial risks. Financial Research, 4(45), 215-222.

Nivorozhkina, L.I., Sinyavskaya, T.G., Polubotko, A.A., Tregubova, A.A. 2018a. Surveybased concept of statistical assessment the deviant financial behavior risks among young people. Statistics - the language of digital civilization: Proceedings of the International scientific and practical conference "II Open Russian Statistical Congress" (Rostov-onDon, December, 4-6), v.1, 204-213.

Nivorozhkina, L.I., Sinyavskaya, T.G., Tregubova, A.A. 2018b. Assessment of risks of deviations of population financial behavior in the economic security system. Financial architectonics and prospects for the development of the global financial system:

Proceedings of the International VII scientific and practical conference (Simferopol, October 10-12, 211-213.

Nivorozhkina, L.I., Sinyavskaya, T.G., Tregubova, A.A. 2019. Statistical study of the tendency of young people for deviant financial behavior. Intelligence, Innovation, Investments, 5, 109-119.

Nivorozhkina, L.I., Sinyavskaya, T.G. 2014. A priori assessment technique of financial institutions' risk associated with individuals. Finance and Business, 1, 87-98.

STATA. 2020. Latent class analysis (LCA). Stata Corp, available at: https://www.stata.com/stata15/latent-class-analysis/.

Synyavskaya, T.G. 2014. Concept of risk analysis of financial behavior of the population in the context of national security. Accounting and Statistics, 3(35), 47-53. 